\title{
0 Executivo como Legislador: A Dinâmica Política em torno da Reforma Educacional Mineira (2003-2014)*
}

\section{Zara Figueiredo Tripodi}

Universidade Federal de Ouro Preto (Ufop), Ouro Preto, MG, Brasil. E-mail:

zarafigueiredo@gmail.com

\section{INTRODUÇÃO}

\begin{abstract}
ssistiu-se, a partir da década de 1980, em boa parte dos países democráticos, um esforço no sentido de aprimorar o desempenho da administração pública, de modo a alcançar melhores níveis de eficiência e eficácia na provisão de serviços públicos, sobretudo aqueles de natureza social. Para tanto, os países começaram a investir em diferentes modelos de gestão, adotando, assim, novos formatos jurídicos e institucionais, muitos deles importados da lógica de gestão privada, dos quais, supostamente, poderiam vir ganhos decorrentes do aprendizado. De um modo geral, as novas ferramentas e estratégias de gestão que passaram a ser adotadas no âmbito da gestão pública, como a flexibilização de políticas de recursos humanos, contratualização de resultados, instituição de metas com consequente premiação ou sanção pelos resultados alcançados e a governança em rede, enfeixam um núcleo de concepções, técnicas e procedimentos a que se convencionou chamar de Nova Gestão Pública ou gerencialismo.
\end{abstract}

\footnotetext{
* Agradeço a Sandra Zákia, Luiz Carlos Bresser-Pereira, Carlos Jamil Cury e Romualdo Portela pelas sugestões apresentadas ao trabalho de tese que deu origem a este artigo. Agradeço, também, os comentários dos pareceristas anônimos da DADOS - Revista de Ciências Sociais. Todas as valiosas contribuições aqui expressas não me exime de possíveis falhas que, porventura, insistiram em permanecer. $\mathrm{O}$ trabalho contou com apoio financeiro do Conselho Nacional de Desenvolvimento Científico e Tecnológico (CNPq) e da Coordenação de Aperfeiçoamento de Pessoal de Nível Superior (Capes).
}

DADOS - Revista de Ciências Sociais, Rio de Janeiro, vol. 61, no 1, 2018, pp. 77 a 101. 


\section{Zara Figueiredo Tripodi}

Embora essa abordagem tenha se pulverizado por vários países, ela não se constituiu, exatamente, em um paradigma de gestão, sendo mais prudente considerá-la como um movimento, que tem se constituído e se reconstituído a partir do contexto em que se insere. Isso porque o nível de aprofundamento de políticas que se alicerçam nos princípios do gerencialismo vai depender de fatores sociais, econômicos e mesmo da tradição política do país ou estado onde se busca implementar determinada política.

De toda forma, um aspecto importante da Nova Gestão Pública ou gerencialismo, conforme definiu Bresser-Pereira (2009), diz respeito àquilo a que se poderia chamar de seus "fundamentos". É nessa direção, que Hood e Jackson (1991) afirmam que a análise de determinada política sustentada pela lógica gerencial não prescinde de se levar em conta, por um lado, que o gerencialismo se configura como um debate administrativo (administrative argument), fundamentado num agrupamento de ideias relativas ao desenho de uma organização, seja privada ou estatal e, por outro, que é necessário que ele seja examinado, também, sob a ótica de uma filosofia administrativa (administrative philosophy), isto é, um corpo de ensinamento doutrinário com ampla aceitação em determinado lugar e tempo, sem que, para isso, tenha havido alguma comprovação científica dos seus pressupostos, mas apenas a capacidade de sua aceitação que se dá, sobretudo, por meio da retórica (Hood e Jackson, 1991).

No cenário brasileiro, o debate em torno da Nova Gestão Pública, bem como a aplicação de seus fundamentos, foi introduzido por meio do Plano Diretor de Reforma do Aparelho do Estado (PDRAE), em 1995, pelo então ministro Luiz Carlos Bresser-Pereira (Mare, 1995). Dentre as características básicas dessa abordagem estão, segundo BresserPereira e Spink (2006), o foco no cidadão e a obtenção de resultados, alcançados a partir de uma administração pautada no pressuposto de que os políticos e os servidores públicos "são merecedores de grau limitado de confiança" (idem:28) e, assim sendo, um dos pilares da Nova Gestão Pública, os contratos de gestão, assumiriam formas apropriadas para se efetivar o controle desses grupos tanto dentro do próprio aparelho estatal, quanto em um relacionamento negociado entre os diversos atores do aparelho do Estado e da sociedade civil (Saravia, 2005).

Embora algumas propostas assentadas na lógica gerencial, concebidas no âmbito federal da reforma do Estado, tenham sido consideradas um 
O Executivo como Legislador: A Dinâmica Política em torno da Reforma...

"fracasso" no campo da educação, segundo o seu próprio idealizador (Bresser-Pereira, 2009), muitos dos seus pressupostos de gestão encontraram terreno fértil nas unidades subnacionais, em decorrência, sobretudo, da migração de técnicos do alto escalão do governo federal para os estados, quando da extinção do Ministério da Administração Federal e Reforma do Estado (Mare), no segundo governo de Fernando Henrique Cardoso (1999-2002).

Em Minas Gerais, estado que concentrava importantes atores que haviam trabalhado no governo Fernando Henrique Cardoso (FHC) e mais especialmente no Mare, os princípios da Nova Gestão Pública se fizeram presentes nos planos de governo da esfera estadual, a partir de 2003, principalmente nas duas gestões de Aécio Neves e de seu sucessor, Antônio Anastasia, ambos do Partido da Social Democracia Brasileira (PSDB).

Tendo, portanto, como referência, as propostas de reforma explicitadas pelos Programas de Governo de Aécio Neves (2003-2006); (2007-2010) e de Antônio Anastasia (2011-2014), examina-se neste artigo a dimensão normativo-legal que as viabilizou, sublinhando a preferência do Executivo pela utilização de leis delegadas e que culmina com a renúncia do Legislativo em legislar sobre a reforma estatal, de modo geral, e sobre a educacional, de maneira específica.

Com base em resultados de pesquisa documental, evidenciam-se a dinâmica legislativa e a trajetória de decisões tomadas que possibilitaram ao Executivo se tornar legislador no seu próprio projeto reformista.

Além dessa introdução, o artigo está organizado em outras quatro seções. A primeira cuida de fazer uma breve contextualização sobre o poder de decreto, por meio do uso de leis delegadas e medidas provisórias. Em seguida, apresenta os antecedentes da reforma mineira, de natureza gerencial, bem como as razões explicitadas para empreendê-la. A terceira seção discute a tramitação do pedido de delegação legislativa feita pelo Executivo mineiro à Assembleia, de modo a legislar sobre a reforma do aparelho de estado e, dentro dela, do campo educacional, assinalando a dinâmica política e o comportamento legislativo que envolveu tal tramitação. Por fim, na sua quarta seção apresenta algumas indicações finais, nas quais argumenta que um dos fatores explicativos do "sucesso" da implementação da reforma foi a atuação de um "Executivo legislador" que, embora agindo dentro dos limites legais, carece de certa legitimidade ética ${ }^{1}$ e tem efeitos sobre a capacida-

DADOS - Revista de Ciências Sociais, Rio de Janeiro, vol. 61, nº 1, 2018 
de democrática da reforma educacional, além de pôr em questão a separação dos três poderes, comprometendo, assim, a accountability horizontal.

\section{O PODER DE DECRETO}

A delegação legislativa, que compreende a Medida Provisória (MP) e a Lei Delegada (DL), também conhecida como poder de decreto, é um instrumento legislativo que consiste, basicamente, em se delegar funções legislativas ao Executivo. Esse instrumento sempre foi um capítulo controverso na história do direito constitucional brasileiro, dividindo opiniões, provocando acalorados debates e chegando mesmo ao Supremo Tribunal, em 2002, no caso de seu uso pelos entes estaduais. Entre o período imperial e a Constituição Cidadã de 1988, a possibilidade de delegação legislativa fez um percurso de positivação e negação nos arranjos institucionais do país, seguido de manifestos favoráveis e contrários ao movimento que se delineava nos textos constitucionais.

A proclamação da República trouxe, como prática do império, a delegação legislativa que, àquela altura, já encontrava opositores no meio jurídico. Na Constituinte da Segunda República, o princípio da proibição foi inscrito expressamente no art. 3o, § 1, da Constituição de 1934 (Leal, 1946).

Assumindo um posicionamento contrário ao de 1934, a Constituição de 1937, no seu art. 12, acolhe a permissão da delegação, de modo a ampliar a liberdade de ação do chefe de Estado (idem). Já o diploma legal de 1946, em seu art. 36, § 2ㅇ, volta a vetá-la a qualquer um dos poderes. Em 1961, com a Emenda Constitucional no 4, a delegação de poderes é acolhida como estratégia para se instituir o sistema parlamentar de governo (Silva, 1963).

Em 1988, os constituintes abrigam a delegação legislativa no direito positivo brasileiro, conferindo ao presidente da República a prerrogativa de utilização da Medida Provisória e da Lei Delegada, com algumas alterações trazidas, posteriormente, pela EC no 32, de 2001.

A incorporação desse dispositivo legal no âmbito federal levou à sua normatização também nas constituições estaduais; indicando, segundo Tomio (2012), duas conclusões: a de que a Constituição Federal teria impulsionado um movimento de reprodução da lógica federal nos es- 
O Executivo como Legislador: A Dinâmica Política em torno da Reforma...

tados, inserindo-a ao processo decisório estadual e, também, que os legisladores estaduais assim o fizeram, "antecipando possíveis dificuldades para os governadores na execução de determinadas políticas" (ibidem:5-6).

No Brasil, os estados de Santa Catarina, Acre, Tocantins, Maranhão, Paraíba e Piauí atribuem ao Executivo estadual a prerrogativa de editar medidas provisórias, enquanto a maioria dos 26 estados brasileiros incorporou às respectivas constituições a prerrogativa de o Executivo estadual editar leis delegadas. Apenas os estados de Piauí, Maranhão, São Paulo, Rio Grande do Sul, Espírito Santo e Amazonas não contemplam o uso de leis delegadas (Tomio, 2012).

De todo modo, independente da opção dos estados em relação ao instrumento legislativo, a sua utilização continua sendo matéria de muitos questionamentos. De um lado, tem-se a crítica formulada desde Oliveira Vianna (1955) e que chega a nossos dias, de que a delegação levaria à hipertrofia do Poder Executivo e, por conseguinte, ao enfraquecimento do Legislativo. De outro lado, tem-se o argumento sustentado pelos defensores do dispositivo legal, como Victor Nunes Leal (1946), na Constituição de 1946, mas, também, por parte significativa dos constituintes de 1988, de que esta seria uma maneira de responder de forma rápida e eficiente às demandas da gestão pública, estando, portanto, voltada às questões da governabilidade.

\section{O DISCURSO OFICIAL E A CONSTRUÇÃO DO CONSENSO}

A intenção de se empreender uma ampla reforma administrativa foi matéria recorrente no Plano de Governo de Aécio Neves (PSDB) “Prosperidade: a face humana do desenvolvimento" (Neves, 2002), bem como esteve presente nos inúmeros discursos proferidos pelo então candidato a governador. No início de 2003, vencida a eleição, ele assume o governo e reafirma o seu objetivo de reformar o aparelho estatal, reorganizando processos, procedimentos e priorizando atividades.

Um dos fatores determinantes da reforma, segundo o discurso oficial, era a crise econômica do estado, que o estaria levando a um delicado quadro fiscal, cujas consequências mais imediatas encontravam-se na falta de recursos para as despesas, inclusive com a folha de pagamento dos servidores que, do seu turno, estavam desestimulados em relação ao futuro do estado. A isso, somava-se, ainda, uma suposta crise de legitimidade. O quadro decorria, segundo Anastasia (2006), de uma soma de fatores negativos, "todos eles vinculados à noção de uma ges-

DADOS - Revista de Ciências Sociais, Rio de Janeiro, vol. 61, nº 1, 2018 


\section{Zara Figueiredo Tripodi}

tão pública não voltada para os resultados, sem critérios de metas e formas de acompanhar o desempenho de órgãos e servidores, a par de uma grave lacuna no processo estadual de planejamento" e, por isso, incapaz de responder às necessidades da população nos diversos setores do governo (ibidem:14).

Assim sendo, a conclusão a que se chegou foi que seria preciso introduzir novos mecanismos de gestão no aparelho estatal, um conjunto de medidas de rápido impacto "para modificar, de uma vez, o padrão de comportamento da Administração estadual". Seria necessário um "choque de gestão" nas estruturas administrativas que possibilitasse racionalizar gastos, além de monitorar e avaliar mais eficazmente as ações e resultados das intervenções governamentais (idem).

Para Aécio Neves, a "necessária mudança" administrativa estabeleceria um novo paradigma de desenvolvimento e de atuação de governo no qual não caberia mais a filosofia desenvolvimentista, caracterizada pelo "Estado-empresário" (Neves, 2002:17). O foco da sua gestão não estaria, segundo ele, na intervenção direta do governo na esfera produtiva, mas no desenvolvimento do capital humano, sendo os meios e o papel desse novo modelo de Estado "a regulação, a coordenação e a indução de projetos, em alianças e parcerias com o setor privado, municípios e setores organizados da sociedade" (idem).

Nessa reorganização, explicitava-se que uma das iniciativas seria a associação do poder público à iniciativa privada, em muitos segmentos, "pelo mecanismo de 'ppp' - parceria público-privada", não se limitando apenas "aos empreendimentos de natureza econômica, mas também aos projetos sociais, por meio das organizações da sociedade civil e dos termos de parceria, introduzindo o terceiro-setor como parceiro preferencial do Poder Público" (Neves, 2002:159).

De modo a reformar o estado e criar um ambiente favorável às mudanças pretendidas, as narrativas engendradas pelos reformistas mineiros consistiam, basicamente, em ideias de transformação, modernização, mudança cultural, rompimento com o passado, mas, sobretudo, eram narrativas alicerçadas no caráter de inevitabilidade e urgência da reforma.

\section{DINÂMICAS POLÍTICAS E O PODER DE DECRETO}

Tendo como um dos argumentos centrais a inevitabilidade de se reformar o estado, sob pena de não ser mais possível implementar políticas 
O Executivo como Legislador: A Dinâmica Política em torno da Reforma...

públicas eficientes, de forma a atender às demandas dos cidadãos, o governador eleito constrói uma aliança com Itamar Franco, àquela altura filiado ao Partido do Movimento Democrático Brasileiro (PMDB), de modo a normatizá-la para, em seguida, começar a sua implementação. Para tanto, o governador recorre ao instrumento da delegação legislativa.

A aliança entre Itamar Franco e Aécio Neves e seus desdobramentos, do ponto de vista da reforma, podem ser explicados pela dinâmica política que perpassa e sustenta as coalizões partidárias no Brasil e que, no limite, tanto pode levar à governabilidade quanto à insustentabilidade de um governo (Avritzer, 2016).

Preterido na convenção do PMDB como candidato ao governo de Minas Gerais, que escolheu o nome do seu vice, Newton Cardoso (PMDB), para concorrer às eleições, Itamar Franco pede a desfiliação do partido. Como a relação do ex-governador com Newton Cardoso sempre fora marcada por conflitos e divergências de opinião, muitas delas explicitamente expostas ao público, Itamar Franco, uma vez afastado do PMDB, envia o ex-embaixador e amigo José Aparecido de Oliveira para convencer Aécio Neves a disputar as eleições para governador contra seu desafeto, tornando-se um dos principais articuladores da campanha do candidato do PSDB e atraindo boa parte da base do PMDB, o que significou, naquele contexto, o apoio de mais de noventa prefeitos do partido (Tripodi, 2014).

Em decorrência dos compromissos firmados entre os dois políticos, tão logo Aécio Neves derrota o candidato do PMDB, saindo vitorioso das eleições para governador, Itamar Franco encaminha uma solicitação ao Legislativo mineiro para que fosse delegada ao governador eleito a prerrogativa de elaborar leis com vistas à implementação da reforma do aparelho estatal.

Assim, em novembro de 2002, Itamar Franco envia uma mensagem à Comissão de Constituição e Justiça do Legislativo, que recebe o $\mathrm{n}^{\mathrm{o}}$ $343 / 2002$, na qual é proposta a delegação de poderes ao governador do estado, a vigorar até $31 / 1 / 2003$, com atribuições para elaborar leis delegadas a fim de alterar a estrutura da administração direta e indireta do Poder Executivo.

O objetivo apresentado na proposição era permitir a racionalização da estrutura administrativa do estado, com poderes limitados a: 1) Criar,

DADOS - Revista de Ciências Sociais, Rio de Janeiro, vol. 61, nº 1, 2018 


\section{Zara Figueiredo Tripodi}

incorporar, transferir, extinguir e alterar órgãos públicos, inclusive autônomos, ou unidades da Administração Direta, bem como entidades da Administração Indireta, definindo suas estruturas básicas, atribuições, objetivos e denominações; 2) Criar, transformar e extinguir cargos em comissão e funções de confiança dos órgãos e entidades a que se refere o inciso anterior, alterar-lhes as denominações e atribuições, definir a natureza de seu recrutamento e fixar-lhes os vencimentos, observados os parâmetros da atual sistemática; 3) Proceder à realocação de atividades e programas no âmbito do Poder Executivo e ao remanejamento de dotações orçamentárias em decorrência da aplicação dos incisos I e II; 4) Alterar vinculações de entidade da Administração Indireta (Minas Gerais, 2002).

A análise da solicitação realizada pela Comissão de Constituição e Justiça da Assembleia Legislativa, primeira instância do parlamento estadual a se debruçar sobre o pedido, e que tem por objetivos avaliar a juridicidade, constitucionalidade e legalidade da proposição, sugere uma emenda relativa aos objetivos que visavam modificar a administração indireta e acaba sendo aprovada, com apenas um voto contrário do Partido dos Trabalhadores (PT). Com o apoio dos aliados na comissão, a mensagem se transforma no Projeto de Resolução no 2.472 / 2002.

Um aspecto curioso do relatório da comissão é que parece haver certo reconhecimento por parte dos parlamentares de que a delegação constituiria um "cheque em branco" para o Executivo, à medida que explicitam em suas conclusões que

eventuais abusos do Executivo na disciplina das matérias enumeradas na resolução superveniente podem ter seus efeitos suspensos por ato deste parlamento, que tem o dever e o poder constitucionais de fiscalizar os atos da administração pública (Minas Gerais, 2002a).

Sete dias após ser aprovada a Comissão de Constituição e Justiça, o Projeto de Resolução - PRE 2.472/2002 segue para a Comissão de Fiscalização Financeira e Orçamentária onde, também, não encontra maiores obstáculos para ser aprovado.

O argumento que sustenta a defesa da aprovação é de que a delegação não geraria despesa para os cofres públicos; além disso, as narrativas engendradas por essa comissão se pautam nas formas de controles externos, como o Tribunal de Contas e a Lei Complementar no 101 / 2000, de Responsabilidade Fiscal, como mecanismos de coibição de even- 
O Executivo como Legislador: A Dinâmica Política em torno da Reforma...

tuais abusos financeiros por parte do Executivo, além da fiscalização que, supostamente, seria exercida pelo próprio Legislativo.

Na Comissão de Administração Pública, o PRE recebe parecer quanto ao mérito, que, na perspectiva dos parlamentares, estaria na necessidade de implementar um novo modo de atuação administrativa e na celeridade do procedimento favorecido pela lei delegada.

Embora o PRE tenha recebido quatro emendas nessa comissão, provenientes do PT, todas foram rejeitadas. Em seguida, após o parecer de $2 \underline{a}$ turno na mesma Comissão de Administração Pública, o PRE no 2.472 / 2002 é aprovado, segue para a Comissão de Redação onde recebe o parecer de redação final. No dia 12 de dezembro de 2002, um mês, portanto, após a chegada da mensagem no 343/2002 ao Legislativo, a Resolução da Assembleia Legislativa é, então, promulgada e publicada no Diário do Legislativo.

Uma vez promulgada a Resolução, já no segundo dia de governo, 2 de janeiro de 2003, Aécio Neves edita a primeira Lei Delegada, de no 49, que dispõe sobre a estrutura orgânica da Administração Pública. Em seguida, ainda no mês de janeiro, haja vista que a delegação deve ser utilizada no prazo de trinta dias, o governador edita mais 62 leis delegadas e produz a força normativa-legal, que implementará a reforma gerencial no estado, de modo geral, e na educação, especificamente. Em 29 de janeiro, o Executivo edita a Lei Delegada no 59, que reestrutura a Secretaria de Estado da Educação.

A primeira lei delegada, de no 49 , introduziu a flexibilização das estruturas administrativas e de recursos humanos, com a redução do número de secretarias; a extinção de cargos comissionados e a criação de cargos temporários considerados estratégicos; a integração de funções da área-meio dos órgãos públicos como planejamento, administração e finanças; a criação de auditorias em cada secretaria, fundação e autarquia, vinculadas à Auditoria Geral do Estado, a fim de controlar os gastos efetuados pelos agentes públicos; e a criação de função gratificada para funcionários de carreira, em substituição aos cargos comissionados.

Foi criado, ainda, no âmbito dessa lei, o Colegiado de Gestão Governamental, cujas atribuições tinham como objetivo buscar o alinhamento do governo com os órgãos setoriais; conceber e articular a execução de

DADOS - Revista de Ciências Sociais, Rio de Janeiro, vol. 61, nº 1, 2018 
programas específicos; acompanhar metas e resultados de programas, além de assegurar a interação governamental.

Já a Lei Delegada no 59, que dispõe sobre a Secretaria de Estado da Educação, além de tratar da sua estrutura orgânica, define objetivos e competências do órgão. Dentre elas, chamam a atenção as contidas no art. $2^{\circ}$, II, IV, V e VI. Esses quatro itens tratam do alinhamento do órgão às diretrizes gerais de Governo, em articulação com a Secretaria de Estado de Planejamento e Gestão; das ações voltadas para o desenvolvimento dos currículos e programas referentes ao desenvolvimento escolar; da instituição da avaliação de desempenho e das parcerias da área educacional com as Organizações da Sociedade Civil de Interesse Público (Oscip), respectivamente.

O exame do conteúdo dessas duas leis delegadas já sinaliza para a reestruturação do aparelho administrativo do Estado de modo a torná-lo compatível com a lógica contratual, que viria a ser disciplinada em julho do mesmo ano, pela Lei Estadual no 14.694/2003, e com a redefinição do papel do Estado, que passaria a atuar por meio de parcerias, conforme determinado pelo marco legal estadual, Lei no 14.870, também de 2003, que institui o modelo de Oscip.

\section{COMPORTAMENTO LEGISLATIVO E LEIS DELEGADAS}

Reeleito em primeiro turno com uma votação expressiva, o segundo mandato do ex-governador Aécio Neves (2007-2010) teve como mote o aprofundamento do programa reformista. Em seu Plano de Governo "Pacto por Minas: estratégias para a transformação social" (Neves, 2006), o então candidato à reeleição afirma que uma segunda geração de "Choque de Gestão" era necessária ao adensamento dos resultados decorrentes da primeira fase da reforma, que reorganizara as estruturas administrativa e legal do Estado, dando-lhe, segundo o discurso oficial, condições de governança em todos os setores.

Além disso, a segunda geração de reforma tinha em vista a integração das agendas social, econômica e fiscal, frequentemente consideradas conflitantes, segundo Guimarães e Campos (2008). O adensamento e a integração da agenda social a que se está referindo relaciona-se aos esforços de alinhamento dos setores sociais, como a educação; e à macropolítica do governo, nessa segunda geração de reforma, inserindo-a na regulação via contratos de gestão. 
O Executivo como Legislador: A Dinâmica Política em torno da Reforma...

Para que os efeitos positivos dos resultados da primeira fase da reforma pudessem, teoricamente, ser sentidos pela sociedade, o plano de governo apresenta como prioridade o estabelecimento de alianças entre os setores público e privado, com o terceiro setor, as universidades, utilizando-se, para isso, "a adoção de metodologia baseada em indicadores de resultados, com gerenciamento intensivo, mediante clara responsabilização dos partícipes pelas metas, projetos e atividades" (Neves, 2006:23). Essa convicção vinha, segundo o candidato à reeleição, de um consenso, "aqui e alhures, de que o crescimento com maior igualdade seria criado por mercados livres e empresa privada" (ibidem:16). Ainda de acordo com o documento, haveria o "aprofundamento de uma obsessiva busca por um Estado de Resultados, com grande preocupação com a qualidade do gasto, amparado no binômio: qualidade fiscal e gestão eficiente" (ibidem:23).

Para levar a termo o aprofundamento da abordagem gerencial, implementando o Programa "Estado para Resultados", o governador recorre novamente ao poder de decreto, concedido mais vez pela Assembleia Legislativa, que, neste segundo momento, permite ao Executivo elaborar 67 leis, quatro a mais que as 63 da primeira gestão.

O Plano de Governo de Aécio Neves, cujo fundamento se pautaria, também, pelo fortalecimento dos princípios democráticos, com o revigoramento do Legislativo, uma vez contraposto à solicitação de leis delegadas para implementar uma nova rodada de reforma aponta, no mínimo, para um grande paradoxo. Primeiro porque não parece razoável que um governo que tenha sido reeleito com significativa aprovação popular e com uma base governista majoritária na Assembleia necessite valer-se do dispositivo de lei delegada. Ademais, contraditório também é o fato de se buscar o revigoramento do Legislativo, discursivamente, e enfraquecê-lo, do ponto de vista factual, afinal, exatamente por sua natureza pouco democrática, o recurso à lei delegada, de acordo com constitucionalistas, é para uso parcimonioso, não para reformar todo um estado.

De toda forma, ainda em 2006, no final do primeiro mandato, por meio da Mensagem no 692/2006, o governador encaminha à Comissão de Constituição e Justiça da Assembleia Legislativa a solicitação para elaborar leis delegadas, nos termos do art. 72 da Constituição do Estado, visando implementar o Programa de Governo "Pacto por Minas: estratégias para a transformação social".

DADOS - Revista de Ciências Sociais, Rio de Janeiro, vol. 61, nº 1, 2018 


\section{Zara Figueiredo Tripodi}

Segundo a mensagem, seria necessária a "reestruturação organizacional dos órgãos e entidades do Poder Executivo, alinhada ao propósito de seguir gastando menos com o governo e mais com a população", por isso mostrava-se imprescindível "o aprofundamento de uma perseguição insistente de um estado de resultados, com grande preocupação com a qualidade do gasto, amparado no binômio: qualidade fiscal e gestão eficiente" (Minas Gerais, 2006a).

A solicitação do Executivo para que o projeto tramitasse em regime de urgência contou com o requerimento do deputado Doutor Viana, do Democratas (DEM), e foi aprovada pela Assembleia.

Um dia antes, porém, de ser examinada pela Comissão de Constituição e Justiça, a solicitação foi objeto de debate em sessão plenária, a que se seguiram outras, marcadas pela disputa das narrativas, entre parlamentares da situação e da oposição, sobre as razões do governo para solicitar uma segunda delegação.

Do lado da base governista, majoritária, a principal tese era formulada em termos da legitimidade do então governador Aécio Neves. Havia um forte consenso entre esses parlamentares de que a delegação de poderes ao Executivo era justificada devido à alta aceitação popular da primeira geração de reforma, expressa na reeleição de Aécio Neves em que obteve $77,3 \%$ dos votos válidos.

É nessa direção que se insere o pronunciamento do deputado Domingos Sávio, do PSDB e de outros parlamentares que se seguiram a ele nos posicionamentos:

E, agora, todos nós que votamos a favor, porque sabemos que Minas Gerais precisa continuar em seu processo de aperfeiçoamento, temos a certeza de que estamos delegando a alguém que já honrou a confiança que a Assembleia lhe depositou há quatro anos. (...) É isso que se espera de um governo que teve $80 \%$ de aprovação e que tem a missão de se auto-superar, de ser melhor do que já foi até hoje. É com essa convicção que votamos a favor, e não com a postura de submissão. O debate é democrático. (...) Tenho certeza de que é isso que o povo mineiro deseja. Se não fosse assim, não daria $80 \%$ de votos ao Governador Aécio Neves (Minas Gerais, 2006b).

A questão central para o debate sobre delegação situa-se, assim, na fronteira entre concentração de poder, por um lado, e ganhos de eficiência, por outro (Melo, 2010). 
O Executivo como Legislador: A Dinâmica Política em torno da Reforma...

O argumento de defesa da base aliada do governador tornou-se, paradoxalmente, o fundamento das objeções apresentadas pelo grupo de oposição a uma nova delegação, qual seja, o governador não precisaria implementar uma reforma pelo poder do decreto já que tinha "legitimidade" expressa pelas urnas.

Haveria, pois, incoerência no fato de um governo de continuidade, com uma base majoritária no Legislativo e com uma votação expressiva no processo eleitoral, recorrer a um mecanismo de "exceção". A lógica que subjaz a essa argumentação é a de que não haveria necessidade de um governo, como o de Aécio Neves, implementar uma nova etapa da reforma sem ampla discussão porque ela não correria o risco de ser rejeitada pela sociedade, uma vez que, como a própria base aliada reiterava, ele havia sido reeleito pela grande maioria. Outro aspecto que não justificaria a utilização da delegação era, justamente, o fato de a base aliada possuir a maioria das "cadeiras" da Casa. A oposição argumentava, ainda, que, sendo um governo de continuidade, teria havido tempo suficiente para planejar a reforma de modo a implementá-la a partir de 2007, principalmente, por já conhecer em minúcias o aparelho estatal por tê-lo reformado no mandato anterior.

Por fim, um dos argumentos mais recorrentes na Plenária, por parte da oposição, situa-se no debate sobre a capacidade democrática das instituições e na divisão e independência dos poderes. É nesse sentido que se insere, por exemplo, o discurso da deputada Jô Moraes, do Partido Comunista do Brasil (PC do B):

(...) Em primeiro lugar, fomos eleitos e eleitas para fazer leis, para legislar, para estruturar o arcabouço jurídico do nosso Estado. Em segundo lugar, fomos eleitos e eleitas para fiscalizar o Executivo e a atividade do Executivo. Esse é o pilar da democracia republicana no nosso país, a interdependência entre o Poder Executivo, o Poder Legislativo e o Poder Judiciário. Fiscalizar o Executivo é um pressuposto fundamental, que garante a transparência. (...) Já não seremos mais a Assembleia Legislativa do Estado de Minas Gerais, mas a assembleia homologatória do Estado de Minas Gerais, porque, com esse projeto, com essa proposta de lei delegada que o Governador Aécio Neves manda a esta Casa, ele nos está tirando o legítimo direito de legislar e fiscalizar a ação do Executivo. O que é mais lamentável é que esse projeto retira desta Casa sua legitimidade e da sociedade, o direito inalienável de discutir suas questões (Minas Gerais, 2006b; ênfase minha).

DADOS - Revista de Ciências Sociais, Rio de Janeiro, vol. 61, nº 1, 2018 
A noção de uma Assembleia "homologatória" acompanhou outros discursos que também buscavam sublinhar possíveis efeitos que mais uma delegação teria sobre o Legislativo, que se enfraqueceria ao ter que renunciar a uma prerrogativa sua. As considerações feitas nessa sessão plenária, com a chegada da proposta do Executivo, não alteraram a tramitação, já que recebeu o reconhecimento da juridicidade, constitucionalidade e legalidade da Mensagem, transformando-a no Projeto de Resolução (PRE) no 3.768/2006.

Obedecendo à mesma dinâmica de 2002, que buscou limitar a delegação aos constrangimentos legais impostos pela Carta Estadual, a Comissão de Constituição e Justiça apresentou duas emendas ao Projeto antes de aprová-lo.

Assim, o PRE 3.768 / 2006 segue para a Comissão de Administração Pública para receber parecer sobre o mérito, tendo, ali, seis propostas de emendas, todas rejeitadas pela Comissão sob o argumento de que as razões que as fundamentavam inviabilizariam a celeridade e a flexibilidade que seriam necessárias à implementação da reforma pretendida pelo Executivo.

Vendo as emendas serem rejeitadas na comissão, seus autores decidiriam levá-las a plenário, objetivando aprová-las nessa instância. Mesmo após os argumentos apresentados em sessão plenária, a tramitação foi concluída em regime de urgência, e as emendas apresentadas e rejeitadas na Comissão de Administração Pública também o foram em plenário.

Na Comissão de Fiscalização Financeira e Orçamentária, o projeto de resolução também logrou êxito, mesmo tendo sido levado a exame em 2 o turno, em razão de um requerimento apresentado pelo deputado Rogério Correia, do PT. Em seguida, a proposição segue para a comissão de redação em 14 de dezembro de 2006 e, no dia seguinte, o presidente da Assembleia, Mauri Torres, do PSDB, que algum tempo depois se tornaria Conselheiro do Tribunal de Contas do Estado, promulga a Resolução 5.294, que permite ao Executivo elaborar mais 67 leis delegadas, quatro a mais que a primeira delegação.

O Programa "Estado para Resultados", tão logo é implementado, viabiliza a formulação de uma agenda educacional regulada por contratos de gestão. A partir daí outros instrumentos que haviam sido introduzidos em gestões anteriores, como em 1991, foram robustecidos 
O Executivo como Legislador: A Dinâmica Política em torno da Reforma...

dentro do "Estado para Resultados". O Sistema Mineiro de Avaliação da Escola Pública que já havia sido reformulado tornou-se ferramenta importante na lógica gerencial implementada, cujo fortalecimento não prescindiu da padronização curricular por meio da criação de um currículo básico comum.

Essas medidas possibilitaram a estruturação de um sistema de metas por escola, pactuadas em contratos de gestão. De modo a intensificar a gestão por resultados, vinculou-se o alcance de metas contratadas a incentivos e à avaliação de desempenho individual do servidor, com efeitos sobre a carreira, não só do ponto de vista da progressão, como também da demissão do servidor público concursado estável, haja vista que o estado regulamentou a Lei Complementar no 71/2003 que institui a avaliação de desempenho individual e disciplina a perda de cargo público por insuficiência de desempenho do servidor público estável.

Em 2011, Antônio Anastasia (PSDB), que se tornou um ator-chave no desenho e implementação da reforma gerencial mineira, sobretudo porque trazia o aprendizado da reforma federal, iniciada com Bresser-Pereira, já que fez parte, àquela altura, da alta burocracia do governo federal, é eleito governador do Estado e sucede a Aécio Neves.

Valendo-se da mesma estratégia, implementa a terceira geração de reforma "Estado em Rede", alicerçada, como o próprio nome sugere, na governança em rede, via utilização de leis delegadas, embora em um número bem menos expressivo que a do seu antecessor.

Um dos fatores explicativos para o número de edição de leis ter sido menor, seis ao todo, relaciona-se ao fato de que as condições necessárias para a efetivação de uma lógica de governo pautada na interação do Estado com atores situados na esfera da sociedade civil - Terceiro Setor - já estavam postas, como afirmou o próprio Anastasia, em seu Plano de Governo:

As condições para essa inovação já estão postas. (...) Essas inovações serão um desdobramento natural da revolução administrativa iniciada por Aécio Neves, que, aprofundada, incrementará a ampla participação da sociedade civil na sua gestão, potencializando assim os impactos nos planos social e econômico (Anastasia, 2010:26).

DADOS - Revista de Ciências Sociais, Rio de Janeiro, vol. 61, nº 1, 2018 


\section{Zara Figueiredo Tripodi}

Do ponto de vista normativo-legal, também estavam postas as condições necessárias para implementar a governança em rede; isso porque, em dezembro de 2003, foi editada a Lei estadual no 14.870, que instituía a qualificação de pessoa jurídica de direito privado como Oscip, no âmbito estadual, e que foi regulamentada, posteriormente, pelo Decreto Estadual no 46.020, de 9 de agosto de 2012.

Possuindo o recurso estratégico que foi a positivação das Oscips, Anastasia fortalece o princípio de interação entre Estado e Terceiro Setor, formalizando várias parcerias, em vários segmentos das políticas públicas, incluindo, aí, a educação.

Dois aspectos trazidos pelo Gráfico 1 apontam para a força que a lógica regulatória de parcerias assumiu no "Estado em Rede". O primeiro deles é a quantidade de organizações qualificadas que, entre 2012 e 2013, atinge um número de 185 Oscips. Intimamente vinculado a esse primeiro, está o segundo aspecto, que é o aumento significativo de Oscips desqualificadas. Se, em 2009, houve uma entidade desqualificadada, em 2013 esse número passa para 113, o que leva a indagar sobre as razões de tais desqualificações. O fato é que, no governo Anastasia, as Oscips assumem uma centralidade nas formas regulatórias do Estado em geral, incluindo a educação.

\section{Gráfico 1}

Número de Entidades Qualificadas e Desqualificadas como

Oscip em Minas Gerais

(2004-2014)

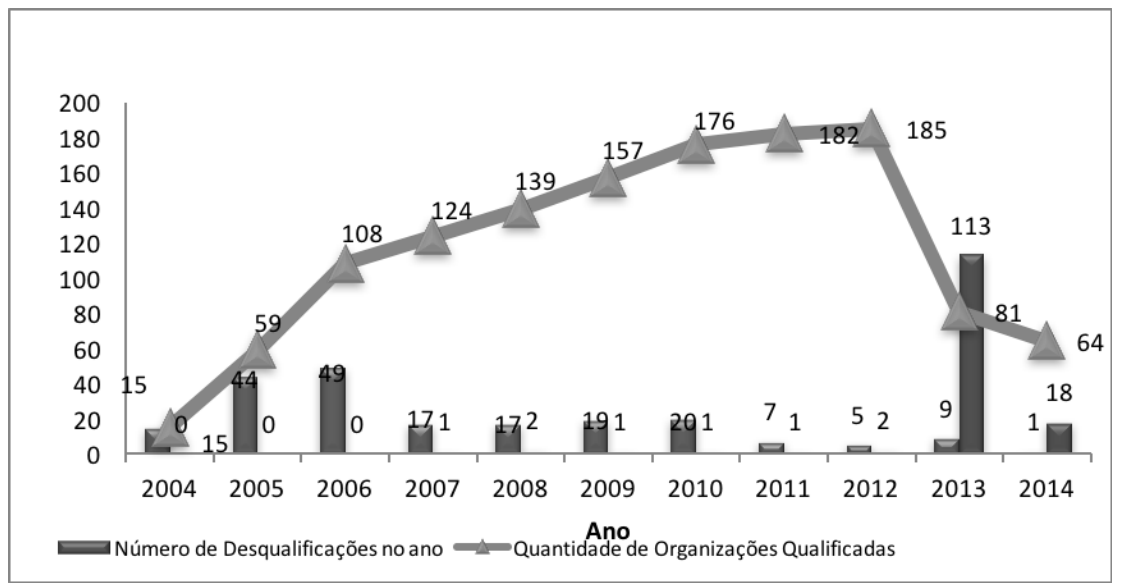

Fonte: Prosdocimi (2014) ${ }^{2}$. 
O Executivo como Legislador: A Dinâmica Política em torno da Reforma...

\section{INDICAÇÕES FINAIS: PODER DE DECRETO E GESTÃO DEMOCRÁTICA DA EDUCAÇÃO}

A crença no potencial de práticas democráticas para a construção de uma qualidade de educação socialmente referendada fez com que a Lei no 13.005, de 2014, que aprova o Plano Nacional de Educação (PNE) para a década 2014-2024, incluísse como uma de suas diretrizes o princípio da gestão democrática da educação pública, com o objetivo de que se articulassem estratégias que pudessem levar à efetivação de decisões democráticas no campo educacional, tanto no chão da escola, quanto nos ciclos de políticas públicas da área.

Em que pese a importância de se incluir em um Plano de Estado, como o PNE, a observância da gestão democrática como elemento articulador de todos os seus eixos constituintes, cabe reconhecer que a capacidade democrática de determinado programa ou política educacional, como acertadamente observaram Sørensen e Torfing (2005), não deve ser medida apenas pelas suas interações internas, mas, também, a sua articulação com o ambiente político dos quais emergem e nos quais também se inserem. Pode-se afirmar, assim, que uma política educacional ou uma reforma são ancoradas em princípios democráticos na medida em que a sua estrutura está adequadamente vinculada a diferentes constituintes políticas e a um relevante grupo de normas democráticas que são, por sua vez, parte do ethos democrático de uma sociedade.

À luz dessas noções é que se torna possível indagar sobre a capacidade democrática da reforma gerencial que começa em 2003 e completa seu ciclo em 2014, tendo em vista que todas as gerações foram implementadas pelo "poder de decreto", sem uma discussão mais ampla com a sociedade, por meio de seus representantes. Ao se privilegiar o instrumento jurídico da Lei Delegada ao invés de Projeto de Lei subtrai-se, quase por completo, a capacidade de a sociedade opinar sobre a reforma, inclusive melhorando a proposta, via parlamento estadual.

Desde os anos que se sucederam à democratização, o período da implementação da reforma gerencial foi o que mais se valeu do poder de decreto, em Minas Gerais, como se pode ver pelo Gráfico 2, organizado por Tomio (2012).

A análise da gramática de normas e condutas de uma política e a sua capacidade democrática permitem endossar a tese que sublinha uma

DADOS - Revista de Ciências Sociais, Rio de Janeiro, vol. 61, nº 1, 2018 
Gráfico 2

Número de Leis Delegadas editadas em Minas Gerais, de 1995 a 2011

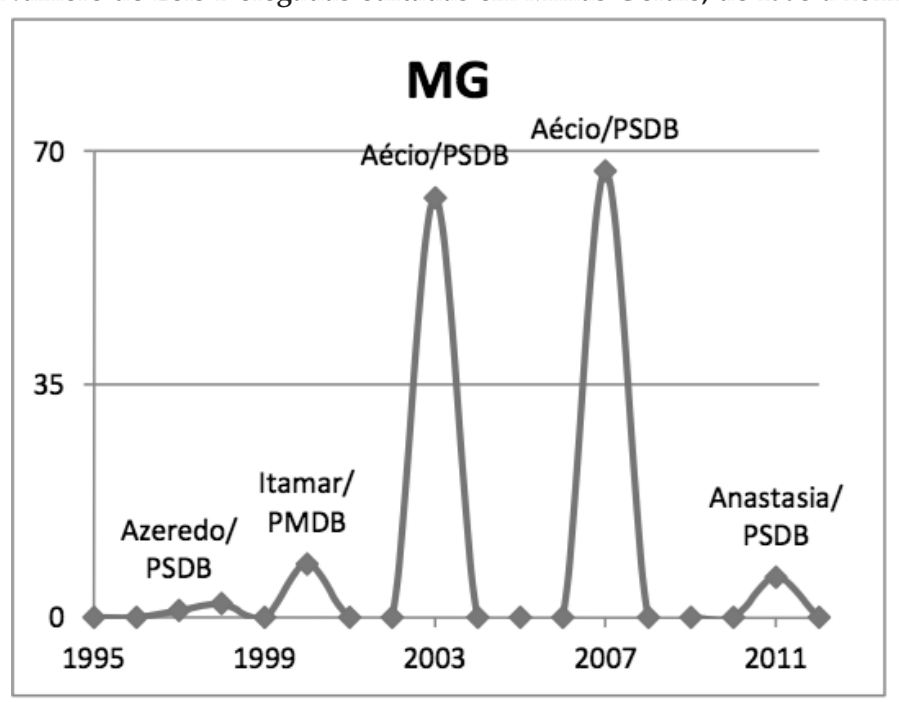

Fonte: Tomio (2012).

associação forte entre poder de decreto e enfraquecimento do Legislativo, na medida em que esse deixa de legislar, além de pôr em questão a própria capacidade do parlamento de fiscalizar o Executivo. Isso porque é a independência de mandatos que converte a accountability horizontal e os checks and balances em elementos essenciais da dinâmica política e da democracia.

É essa direção que Baracho (2007) apontava ao afirmar que o excesso de delegação estava matando o Legislativo estadual, em Minas, tendo em vista que "é uma carta-branca".

A utilização do direito constitucional como meio de governo "por razões de conjuntura e imposta por critérios de racionalidade material" também foi objeto de Faria (1985), para quem a opção por instrumento de exceção levaria ao esvaziamento do equilíbrio entre os poderes, a hierarquia das leis, o controle de constitucionalidade, o princípio da legalidade e, no limite, a um retrocesso autoritário.

(...) Desse modo, soberanos não são mais o Legislativo e o Judiciário, mas os órgãos regulamentadores e executores do Executivo. É por essa razão que a conversão do direito num simples instrumento de governo - quase sempre justificado em nome da nobreza dos fins e das boas in- 
O Executivo como Legislador: A Dinâmica Política em torno da Reforma...

tenções dos governantes - encerra um grande risco de retrocesso autoritário (Faria, 1985:100).

Há autores, por outro lado, que defendem a tese de que o poder de decreto no âmbito estadual não leva à hipertrofia do Executivo, tendo em vista que governadores, mesmo sem esse instrumento, controlariam a já limitada agenda decisória nos estados e, ainda, que a autonomia para legislar dos entes estaduais encontraria limitações impostas pelo desenho federativo brasileiro, que atribui a eles a competência de legislar de forma concorrente com a União (Tomio, 2012).

A questão é que a delegação legislativa, no seu valor intrínseco, deve ser examinada não somente à luz do plano jurídico, mas, também, do plano político. Isso significa dizer que o "Poder Executivo pode utilizar os poderes de agenda para perpetuar os poderes de agenda que lhe foram concedidos a partir de uma escolha constitucional original e democrática" (Melo, 2010:66), assim como formular um conteúdo de agenda em bases pouco democráticas.

No caso da reforma educacional, as leis delegadas representaram o meio pelo qual se alterou um modo regulatório, introduzindo na atividade pública um ethos privado que se materializa na contratação de metas pelas escolas, na produção de rankings, na premiação ou punição dos profissionais da escola diante dos resultados do rendimento de alunos em avaliação em larga escala, na publicação de resultados do Índice de Desenvolvimento da Educação Básica (Ideb) na frente das escolas e na possibilidade de oferta de educação via Terceiro Setor.

Todas essas ferramentas, tomadas em conjunto, constroem um cenário no qual se pode reconhecer o "mercado educacional" apontado por Dale (1994) e cujo desenho final poderá se efetivar pela instituição da Public Choice Theory, ou a teoria da escolha. Afinal, todos os elementos já estão postos e foram, cuidadosamente, construídos ao longo de três gestões, por meio de decreto, sem debates: tem-se o "cliente" (aluno); o produto (ensino); a informação sobre esse produto (placas de Ideb); e, por fim, um leque de ofertas via Terceiro Setor.

Se não é possível imputar à reforma gerencial na educação o caráter de ilegalidade, já que a delegação está assentada no direito positivo, é possível dizer que ela carece de certa legitimidade ética na medida exata em que a força normativa que a viabilizou logrou êxito pela atuação de um Executivo que se tornou legislador, contrariando a premissa

DADOS - Revista de Ciências Sociais, Rio de Janeiro, vol. 61, no 1, 2018 
lockeana da constituição de um governo legítimo, segundo a qual o poder do Legislativo, tendo derivado do povo por concessão voluntária, "implica somente em fazer leis e não em fazer legisladores, e o Legislativo não terá o poder de transferir a própria tarefa de fazer leis para outras mãos" (Locke, 2010:96).

(Recebido para publicação em 25 de Julho de 2016)

(Reapresentado em 26 de Setembro de 2017) (Aprovado em 19 de Novembro de 2017) 
O Executivo como Legislador: A Dinâmica Política em torno da Reforma...

\section{NOTAS}

1. Nesse artigo, o conceito de "legitimidade ética" é utilizado conforme formulado em tese de doutoramento (Tripodi, 2014), e que, em linhas gerais, significa a necessidade de introduzir uma dimensão ética aos processos de produção legal, ultrapassando, assim, a observância da aprovação da lei por maiorias significativas e o cumprimento de procedimentos formais, implicando a necessidade de se considerar, também, os efeitos dos atos legais produzidos sobre as instituições e, ainda, sobre aqueles afetados pelas decisões políticas.

2. O Gráfico 1, embora faça parte de artigo produzido por Vilhena e Prosdocimi (2013), foi atualizado, e a versão que se encontra no presente artigo resulta do estudo de Eduardo Campos Prosdocimi que, em 2014, concedeu uma entrevista informal à autora, no âmbito do doutorado, e o disponibilizou, já que, à época, era servidor do Núcleo Central de Parcerias com as Organizações da Sociedade Civil de Interesse Público (NCPO), no governo do estado de Minas Gerais. 


\section{Zara Figueiredo Tripodi}

\section{REFERÊNCIAS BIBLIOGRÁFICAS}

ANASTASIA, Antônio. (2006), "Antecedentes e Origem do Choque de Gestão", in R. Vilhena et al. (orgs.), O Choque de Gestão em Minas Gerais: Políticas de Gestão Pública para o Desenvolvimento. Belo Horizonte, Editora UFMG, pp. 14-17.

(2010), "Minas de Todos os Mineiros. As Redes Sociais de Desenvolvimento Integrado". Plano de Governo 2011-2014. Belo Horizonte.

AVRITZER, Leonardo. (2016), Impasses da Democracia no Brasil. Rio de Janeiro, Civilização Brasileira.

BARACHO, José Alfredo. (2007), "Aécio Neves Ganha Aval para 'Fazer' Leis". Folha de S. Paulo, 11 de março. Disponível em http://www1.folha.uol.com.br/folha/brasil/ult96u90180.shtml. Acesso em 29/5/2016.

BRESSER-PEREIRA, Luiz Carlos. (2009), “Os Primeiros Passos da Reforma Gerencial do Estado de 1995", in P. C. Medeiros; E. Levy (orgs.), Novos Caminhos da Gestão Pública: Olhares e Dilemas. Rio de Janeiro, Qualitymark, pp. 3-44.

BRESSER-PEREIRA, Luiz Carlos; SPINK, Peter. (2006), Reforma do Estado e Administração Pública Gerencial. Rio de Janeiro, FGV Editora, pp. 173-199.

DALE, Roger. (1994), "A Promoção do Mercado Educacional e a Polarização da Educação". Educação, Sociedade e Culturas, no 12, pp. 109-139.

FARIA, José Eduardo. (1985), “Legalidade e Legitimidade: O Executivo como Legislador". Revista de Informação Legislativa, vol. 22, no 86, pp. 93-104.

GUIMARÃES, Tadeu Barreto; CAMPOS, Eder Sá Alves. (2008), “Gestão da Estratégia no Governo do Estado de Minas Gerais: Em Busca da Harmonia entre a Ação e os Resultados". Anais do XIII Congreso Internacional del Clad sobre la Reforma del Estado y de la Administración Pública. Buenos Aires, Clad.

HOOD, Christopher; JACKSON, Michael W. (1991), Administrative Argument. Aldershot, Dartmouth Publishing Company.

LEAL, Victor Nunes. (1946), “Delegações Legislativas". Revista de Direito Administrativo, vol. 5, pp. 378-390.

LOCKE, John. (2010), Segundo Tratado sobre o Governo. São Paulo, Martins Claret.

MARE (Ministério da Administração Federal e Reforma do Estado). (1995), Plano Diretor da Reforma Administrativa do Aparelho do Estado. Brasília, Mare.

MELO, Marcus André. (2010), "Controle do Poder Executivo e Presidencialismo de Coalizão". Cadernos Aslegis, vol. 40, pp. 55-78.

MINAS GERAIS. (2002), “Mensagem no343/2002”. Diário do Legislativo. Belo Horizonte.

. (2002a), "Parecer da Comissão de Constituição e Justiça sobre a mensagem no 343/2002". Diário do Legislativo. Belo Horizonte.

. (2006a), “Mensagem no 692/2006". Diário do Legislativo. Belo Horizonte.

(2006b), “Ata da 58a Reunião Extraordinária da 4ạ Sessão Legislativa Ordinária da 15a Legislatura". Diário do Legislativo, 6 de dezembro. 
O Executivo como Legislador: A Dinâmica Política em torno da Reforma...

NEVES, Aécio. (2002), Prosperidade: A Face Humana do Desenvolvimento. Plano de Governo 2003-2006. Coligação Minas Unida.

(2006), Pacto por Minas: Estratégias para a Transformação Social. Plano de Governo 2007-2010. Coligação Minas não pode parar.

OLIVEIRA VIANNA, Francisco José de. (1955), Instituições Políticas Brasileiras. Rio de Janeiro, José Olympio Editora.

SARAVIA, Enrique. (2005), Contratos de Gestão como Forma Inovadora de Controle das Organizações Estatais. Trabalho apresentado no X Congreso del Clad, Chile, 18-21 de outubro.

SILVA, Carlos Medeiros. (1963), "A Legislação Delegada". Revista de Direito Administrativo, vol. 71, pp.1-15.

SØRENSEN, Eva; TORFING, Jacob. (2005), “The Democratic Anchorage of Governance Networks". Scandinavian Political Studies, vol. 28, no 3, pp. 195-218.

VILHENA, Renata M. de Paes; PROSDOCIMI, Eduardo Campos. (2013), Modelo Mineiro de Parcerias com Oscips: Uma Análise Comparativa do Processo de Seleção da Entidade Apta a Firmar Termo de Parceria. Trabalho apresentado no VI Congresso Consad de Gestão Pública. Brasília, 16-18 de abril.

TOMIO, Fabricio R. de Limas. (2012), Delegação de Poderes: Medida Provisória e Lei Delegada no Processo Legislativo Estadual. Trabalho apresentado no 8 Encontro da $\mathrm{ABCP}$, Gramado, 1-4 de agosto.

TRIPODI, Maria do Rosário Figueiredo. (2014), A Instituição da Agenda Contratual na Educação Mineira: Arquitetura de uma Reforma. Tese (Doutorado em Educação) Faculdade de Educação, Universidade de São Paulo, São Paulo. 


\section{Zara Figueiredo Tripodi}

RESUMO

O Executivo como Legislador: A Dinâmica Política em torno da Reforma Educacional Mineira (2003-2014)

Este artigo examina a instituição da agenda reformista na educação mineira, no período de 2003 a 2014, do ponto de vista normativo, analisando a trajetória de decisões tomadas e as posições assumidas pelo Parlamento Estadual em torno do uso de delegação legislativa. Para tanto, utilizou-se análise documental e de conteúdo. Evidencia-se que a decisão do Legislativo em delegar sua prerrogativa de legislar sobre a reforma da educação, de natureza gerencial, estava assentada em uma dinâmica institucional e em uma estrutura de incentivos que permitiram ao Executivo atuar como legislador. Conclui-se, finalmente, que a despeito da sua constitucionalidade, a delegação traz implicações para a educação socialmente referendada, como também tem efeitos sobre a capacidade democrática da reforma educacional.

Palavras-chave: reforma educacional; Nova Gestão Pública; comportamento legislativo; produção normativa; capacidade democrática

\section{ABSTRACT \\ The Executive Branch as Legislator: The Political Dynamic Surrounding Educational Reform in Minas Gerais (2003-2014)}

The following article examines the institution for educational reform in the Brazilian state of Minas Gerais in 2013 to 2014 from a normative perspective, analyzing the trajectory of decisions made and positions assumed by the state parliament on the use of the delegation of legislative power, by means of an analysis of documents and content. We demonstrate that the Legislative Branch's decision to delegate its prerogative to legislate on educational reform in a management sense was based on an institutional dynamic and on a structure of incentives allowing the Executive to behave as a legislator. It finishes by concluding that, despite its constitutionality, such a use of delegation has implications on socially sanctioned education, as well as effects on the educational reform's democratic capacities.

Key words: educational reform; New Public Management; legislative behavior; normative production; democratic capacities 
O Executivo como Legislador: A Dinâmica Política em torno da Reforma...

RÉSUMÉ

L'Exécutif comme Législateur: La Dynamique Politique entourant la Réforme de l'Éducation dans l'État de Minas Gerais (2003-2014)

Cet article analyse sous l'angle normatif les réformes menées dans l'éducation de l'État de Minas Gerais entre 2003 et 2014. On étudiera à cette fin les décisions prises et les positions assumées par le Parlement de l'État en ce qui concerne l'usage de la délégation législative, ce pour quoi on a utilisé l'analyse documentaire et de contenu. On a mis en évidence que la décision du Pouvoir législatif de déléguer ses prérogatives de légiférer sur la réforme de la gestion de l'éducation était fondée sur une dynamique institutionnelle et une structure de soutien qui a permis à L'Exécutif d'agir en législateur. On en a conclu qu'en dépit de sa constitutionnalité, la délégation en question a eu des conséquences sur une éducation socialement marquée, mais également sur la capacité démocratique de la réforme de l'éducation.

Mots-clés: réforme de l'éducation; forme d'éducation; Nouvelle Gestion publique; comportement législatif; production normative; capacité démocratique

\section{RESUMEN}

El Poder Ejecutivo como Legislador: La Dinámica Política en torno a la Reforma Educativa de Minas Gerais (2003-2014)

Este artículo examina el establecimiento de la agenda reformista en la educación del estado brasileño de Minas Gerais, entre 2003 y 2014, desde un punto de vista normativo, analizando la trayectoria de decisiones tomadas y las posiciones asumidas por el parlamento estatal en torno al uso de delegación legislativa. A tal efecto, se recurrió a un análisis documental y de contenidos. Se hace evidente que la decisión del poder legislativo de delegar su prerrogativa de legislar sobre la reforma de la educación, de naturaleza directiva, estaba asentada en una dinámica institucional y en una estructura de incentivos que permitieron al poder ejecutivo actuar en calidad de legislador. Por último, se concluye que, pese a su constitucionalidad, la delegación tiene implicaciones para la educación socialmente refrendada, del mismo modo que influye en la capacidad democrática de la reforma educacional.

Palabras clave: reforma educativa; nueva gestión pública de Brasil; comportamiento legislativo; producción normativa; capacidad democrática

DADOS - Revista de Ciências Sociais, Rio de Janeiro, vol. 61, nº 1, 2018 